\title{
Measuring Technical Efficiency of Cars: A Field Investigation in the Italian Domestic Market
}

\author{
Corrado lo Storto \\ DIEG, School of Engineering, University of Naples Federico II, Naples, Italy \\ corrado.lostorto@unina.it
}

\begin{abstract}
This paper implemented Data Envelopment Analysis to develop a measure of technical efficiency (TE) for a car. The measurement of TE uses published technical data and judgements by industry experts. It is assumed that the technical value of a car is a function of a functional feature performance set of the product delivered to users when bearing some usage and ownership costs. TE is calculated for a sample of 216 cars sold in the Italian market from the 1970 s to the early 1990s.

Index Terms - Data Envelopment Analysis, car, technical efficiency, product technical value, benchmarking.
\end{abstract}

\section{Background}

Since the 1960s the car industry all over the world has gone through an intense transformation to meet the challenges coming from the market - both as customer preferences and competition, environmental regulations, greater concern for safety and pressure and opportunities offered by new technologies. Innovation in the auto industry has consequently assumed major significance. Measuring the technical efficiency that a car is delivering to consumers is henceforth of paramount importance in order to indentify trajectories for improving the product and make it more competitive and appealing in the market.

Literature provides several conceptualization of a product as a: set of physical actions and objects ${ }^{1}$, satisfaction generating system ${ }^{2}$, psychosocial symbol $^{3}$, set of causal concepts $^{4}$, experience ${ }^{5}$, offering ${ }^{6}$, set of features ${ }^{7}$, technology ${ }^{8}$. While in the economic and marketing-strategy literature there was a terrific proliferation of contributions as to most of the proposed conceptualizations with a rich dissemination of insights from one perspective to the other and from the theory to the practice, there was a relative scarce attention of scholars to the two latter ideas of product as a technology embodiment system capable of delivering a set of functionalities to users and a parallel indifference of practitioners for this. A major concern of scholars to this latter perspective of product analysis could help managers to make sound decisions and plans. The identification of the technical value, and in particular, the technical efficiency of a product as a measure of its capability to provide the user with benefits associated to a set of functionalities suffering some ownership and usage costs, could be useful to disclose uncertainty and ambiguity relatively to several management matters, i.e. the correct product positioning in order to understand better the nature of competition relative to certain types of product features, the relative assessment of the whole set of product performance, the way to increasing product performance by improving specific technological and functional features. Particularly, this comparative evaluation may provide insights as to how products might be developed to fit more closely with markets needs and to give the firm a competitive edge. Moreover, measuring technical efficiency and positioning of the product allows to identify gaps, segments or niches within some segment of the market. If such a gap is found, it represents a market opportunity that might be an opportunity for the firm. Product positioning based on a sound benchmarking of technological and functional features might be used to display competitive relationships and temporal changes in a manner that is similar in appearance to a perceptual map. Naturally, these analyses support rather than substitute for the perceptual data that can be provided by customers. The measurement of technical efficiency and mapping of product features can contribute insights into current and prospective product offering, and help to find opportunities for product improvement and new product development. The state of technology does not remain static either in the short or the long run. In the short run for instance, one way that products compete is by leapfrogging each other in terms of performance - whether measured in speed, quality, power, etc. When used as an average measure relative to certain periods of time, the product technical efficiency can be useful either to provide a picture of the technology state in that product market, or to trace the evolution of the technical value of the product in a given market segment over time, thus making it possible to analyse the output-input causal relationships between performance, technology, and costs.

This paper implements Data Envelopment Analysis (DEA) to get a measure of car technical efficiency. This measure is calculated for a sample of 216 cars sold in the Italian domestic market from the 1970 s to the 1990 s.

\section{A Measure of a Car Technical Efficiency}

In order to measure the technical efficiency of a car, it is preliminarily necessary to assess the technological capability of that car to deliver functionalities to the user. The problem of measuring the technological capability of a product can be approached from two different perspectives. The first one is to consider several similar products sold in the market in different times, to analyze each product as a system and evaluate the technological capability of every component or part included in the product and the way it interacts with the others. This approach is typical of value engineering analysis. In most cases, this is a difficult and burdensome way to compare products in terms of their technical value. That is evident for those products incorporating thousands of parts 
and components like a plane or a car. A second perspective is to consider a product as a "black box" and characterize its embodied technology set by the performance of the yielded output associated to a cluster of functionalities $F_{i}$ delivered to users relevant for that product ${ }^{9-12}$. It considers a product as a bundle of different features ${ }^{7,13}$. Different approaches have been proposed: scoring models ${ }^{14}$, trade-off between technological parameters surfaces ${ }^{15}$, objective sector functions ${ }^{16}$. This perspective is known in the literature as "functional perspective"17,18.

In this study, the second perspective was adopted. A car is considered as a system incorporating several technologies, i.e. the technology of metal working, alloys moulding, engine combustion, electronic control, safety, comfort, etc., and the integration of all them deliver functionalities to the user. The rationale behind this conceptualization of a car as a bundle of technologies and functional features finds its justification in the following reasoning. When a consumer buys a car, he/she buys some benefits, i.e. mobility, quality, comfort, safety, etc., but bearing some costs for the use and ownership of the product. Car technologies are generally hidden to most of its users. Indeed, they have only a rough idea of them from their effects, measured by the performance set associated to functional features, i.e. the engine power, the engine torque, the maximum speed, the level of comfort, and so on. Measurements for these parameters or features give a quantitative indication of the benefits offered to consumers and, at the same time, of the nature of technology embodied in a car. The technical value of a car (CTV) is henceforth assumed to be a function of the performance set $\left(\mathrm{FP}_{\mathrm{i}}\right)$ associated to functional features $F_{1}, F_{2}, \ldots, F_{n}$ :

$$
\mathrm{CTV}=f\left(\mathrm{FP}_{1}, \mathrm{FP}_{2}, \ldots, \mathrm{FP}_{\mathrm{n}}\right)=\Sigma \mathrm{w}_{\mathrm{i}} \mathrm{FP}_{\mathrm{i}}
$$

The CTV is a measure of the overall benefit a car deliver to users. The technical efficiency of a car can purposefully be measured as the ratio of the CTV measure to the amount of costs $C_{1}, C_{2}, \ldots, C_{m}$ that the users have to bear to benefit functional features $F_{1}, F_{2}, \ldots, F_{n}$ :

$$
\mathrm{TE}=\frac{\mathrm{CTV}}{\sum \mathrm{v}_{\mathrm{i}} \mathrm{C}_{\mathrm{i}}}
$$

Thus, technical efficiency measures the relative benefit the users gain when using a car.

\section{Measuring Technical Efficiency Through Data Envelopment Analysis}

Data Envelopment Analysis (DEA) is extensively used by scholars to identify the production frontier and measure efficiency rates in several industries. Like other methods, i.e. the stochastic production frontiers, DEA estimates the maximum potential output for a given set of inputs. However, DEA provides efficiency relative measurements of a specific unit by estimating an empirical production function frontier from multiple inputs and outputs relative to a sample of homogeneous units implementing a linear programming technique $^{19}$. The production frontier is generated solving a sequence of linear programming (LP) problems, one for each unit included in the sample, while the relative efficiency score of a unit is measured by the distance between the actual observation and the frontier obtained from all the units under examination, adopting the Farrell measure of technical efficiency (TE) as a measure for the unit efficiency score. Efficiency is thus evaluated as the classical engineering ratio of outputs to inputs. Given the set of units, the model determines for each unit the optimal set of input weights and output weights that maximize its efficiency score. DEA does neither require any explicit assumption about the underlying relation between inputs and outputs nor the a priori knowledge of weights to be assigned to assess efficiency.

In this study, technical efficiency is measured by implementing an input-oriented DEA model constructing the production function by searching for the maximum possible proportional reduction in input usage, while output levels are held fixed. As the Italian market includes cars classified into 9 market segments for their extremely different characteristics, technical efficiency was calculated assuming variable returns to scale (VRS) (BCC model). ${ }^{20}$ An input-oriented BCC LP model is defined as:

$$
\begin{array}{ll}
\text { Min } \Theta+\varepsilon\left[\sum_{i=1}^{m} S_{i}^{-}+\sum_{r=1}^{s} S_{r}^{+}\right] & \\
\text {s.t. } & \sum_{j=1}^{n} \lambda_{j} y_{r j}-S_{r}^{+}=y_{r j}, \quad r=1, \ldots, s \\
& \sum_{j=1}^{n} \lambda_{j} x_{i j}+S_{i}^{-}=\Theta x_{i j}, \quad i=1, \ldots, m \\
& \sum_{j=1}^{n} \lambda_{j}=1 \\
\lambda_{j} \geq 0 \quad & j=1, \ldots, n \\
S_{r}^{+}, S_{i}^{-} \geq 0 \quad r=1, \ldots, s, i=1, \ldots, m
\end{array}
$$

where $\sum \lambda_{\mathrm{j}}=1$ is the convexity constraint added to the CCR model $^{21}$ that assumes constant returns to scale. As the standard development of the DEA model produces an efficiency measure which is between 0 and 1 , and does not generate a ranking of units, the original CCR model was modified introducing the concept of super-technical efficiency (STE) ${ }^{22}$ that makes the efficiency analysis more discerning and provides a full not censored ranking of units efficiency (AP DEA model). An efficiency score of a car $\mathrm{k}$ greater than $100 \%$ may thus be measured ${ }^{23,24}$.

\section{The Implementation Of DEA In The Italian Car Market}

The technical efficiency model includes 4 outputs (car performance features) and 2 inputs (costs) that were obtained as functions of car technical data and expert subjective judgments (Table 1): 
Table A.1 in Appendix displays details about input and output measurement. Car prices were adjusted having as reference the 1993 consumer price index. All selected cars were identified in the specialized trade literature. Cars are ordinary passenger cars that have been equipped with conventional spark ignition petrol engines or turbocharged spark ignition engines. The need to assess and compare subjectively features required the researcher to consult an expert of the automotive field. Three sub-samples of petrol cars sold in the Italian market were considered (37 cars present in the market between 1970 and 1972, 82 in the years 1980-82, 97 between 1990 and 1993). Sub-sample were selected with the aim of having a good mix of all cars sold in Italy in that period. The data were collected from technical and trade literature ${ }^{25,26}$.

Table. 1. DEA input and output variables

\begin{tabular}{|l|l|}
\hline VARIABLES & DATA/JUDGMENTS RELATIVE TO: \\
\hline Outputs & \\
\hline ENGINE & engine power, torque, capacity, car mass \\
\hline MOBILITY & max speed, acceleration, pick up \\
\hline SAFETY & braking space and quality, safety equipment \\
\hline QUALITY & $\begin{array}{l}\text { noise, comfort, internal fittings, space, ventilation, } \\
\text { equipment, driving }\end{array}$ \\
\hline Inputs & \\
\hline PPC & car price (1993 consumer price index) \\
\hline PUC & average fuel consumption \\
\hline
\end{tabular}

\section{Results}

Table 2 reports the outcome of DEA. Both the average TE and STE decreased from the 1970s to 1980s, but increased moving to 1990s. The standard deviation regularly decreases from 1970s to 1990s, showing a lower variation of technical efficiency scores across cars in the 1990s and a polarization of car efficiencies around higher values in comparison to previous two decades. Table 2 displays the number and ratio of efficient cars $(T E=1.0)$ to total number of cars in subsamples, too. These latter data confirm previous statistical data showing a considerable increase of $100 \%$ efficient cars in the 1990s.

Table. 2. Technical efficiency and super-efficiency scores

\begin{tabular}{|c|c|c|c|c|c|c|}
\hline \multirow{2}{*}{} & \multicolumn{2}{|c|}{1970 s } & \multicolumn{2}{c|}{1980 s } & \multicolumn{2}{c|}{1990 s } \\
\cline { 2 - 7 } & mean & st.dev & mean & st.dev & mean & st.dev \\
\hline TE & 0.847 & 0.105 & 0.82 & 0.083 & 0.929 & 0.066 \\
\hline STE & 0.855 & 0.120 & 0.84 & 0.180 & 1.013 & 0.281 \\
\hline & & & & & & \\
\hline efficient & 4 & & 4 & & 29 & \\
\hline \%efficient & 10.8 & & $4.9 \%$ & & 29.9 & \\
\hline
\end{tabular}

Table 3 reports the results of a forward stepwise regression analysis performed with the aim to identify more critical variable influencing efficiency. The STE score for all 216 cars was considered as the dependent variable, while the input and output variables were included in the regression model as independent variables.
Table. 3. Stepwise regression analysis (all sample)

\begin{tabular}{|l|l|l|l|l|}
\hline & & coefficient & $\mathrm{t}$ & prob. \\
\hline INTERCEPT & & 0.619 & 6.582 & 0.000 \\
\hline ENGINE & & -1.200 & -5.073 & 0.000 \\
\hline PERFORMANCE & & 1.376 & 3.783 & 0.000 \\
\hline SAFETY & & 0.810 & 5.010 & 0.000 \\
\hline QUALITY & pooled & & & \\
\hline PPC & pooled & & & \\
\hline PUC & & -0.624 & -2.901 & 0.004 \\
\hline \multicolumn{5}{|l|}{} \\
\hline F: 18.945, prob: 0.000 & & & & \\
\hline r-squared: 0.411 & & & \\
\hline
\end{tabular}

Four variables are mostly influencing the efficiency score of cars in sample: ENGINE, MOBILITY, SAFETY, and PUC. The examination of coefficient signs reveals that, as expected, MOBILITY and SAFETY positively affect the efficiency score, PUC has a negative effect on efficiency, but - not expected - ENGINE is negatively correlated to efficiency. Furthermore, MOBILITY has a greater effect than SAFETY, and PUC, even though negatively influences efficiency, has a less critical impact.

Tables 4-5 show the outcome of the forward stepwise linear regression analyses performed relative to specific subsamples in the years 1990s and 1980s only. Due to the small number of cases for the 1970s sub-sample, regression was not performed.

Table. 4. Stepwise regression analysis (years 1990s)

\begin{tabular}{|l|l|l|l|l|}
\hline & & coefficient & $\mathrm{t}$ & prob. \\
\hline Intercept & & 0.027 & 0.091 & 0.928 \\
\hline ENGINE & pooled & & & \\
\hline MOBILITY & pooled & & & \\
\hline SAFETY & pooled & & & \\
\hline QUALITY & & 1.253 & 3.317 & 0.001 \\
\hline PPC & pooled & & & \\
\hline PUC & pooled & & & \\
\hline & & & & \\
\hline F: 10.999, prob: 0.001 & & & \\
\hline r-squared: 0.106 & & & & \\
\hline
\end{tabular}

Table. 5. Stepwise regression analysis (years 1980s)

\begin{tabular}{|l|l|l|l|l|}
\hline & & coefficient & $\mathrm{t}$ & prob. \\
\hline Intercept & & 1.541 & 9.041 & 0.000 \\
\hline ENGINE & & -2.491 & -8.894 & 0.000 \\
\hline MOBILITY & & 2.896 & 7.494 & 0.000 \\
\hline SAFETY & pooled & & & \\
\hline QUALITY & & -0.729 & -3.401 & 0.001 \\
\hline PPC & & 0.885 & 3.035 & 0.003 \\
\hline PUC & -1.089 & -3.911 & 0.000 \\
\hline \multicolumn{5}{|l|}{} \\
\hline F: 18.843, prob: 0.000 & & & \\
\hline r-squared: 0.553 & & & \\
\hline
\end{tabular}


The great differences between the two regression analyses as to the behavior of the coefficients (size and sign) reveals that the car market characteristics substantially changed from the 1980s to the 1990s. While in the 1980s factors affecting technical efficiency were easily identifiable, in the 1990s the market structure became more variegated, internationally exposed, and the great number of niches makes it difficult to extrapolate average trends and cause-effect linkages. In the 1990s only the QUALITY performance feature is statistically significative, positively associated to STE. In the 1980 s, as expected, the ownership cost (PPC) positively affects STE, while this latter diminishes when fuel consumption (PUC) increases. Vice versa, QUALITY, and much more, ENGINE are unexpectadly negatively associated to STE.

\section{Conclusions}

A method for measuring the technical efficiency of a car has been proposed. The method is based on the implementation of Data Envelopment Analysis and uses factors that are objectively measurable in terms of the technical features of the engine, the performance features of the car, and factors subjectively measurable in terms of the quality and safety level of the car. This approach has the advantage of simplicity, and can be usefully adopted for several purposes: to identify benchmarks in the market; to keep trace of technology and technology advance in the market; to identify the features which the car manufacturers should mostly focus on.

Even though the primary aim of this paper was to illustrate the method and its implications, the implementation of the method on a sample of 216 cars sold in the Italian market between the early 70s and the early 90s shows some interesting insights. In particular, the method has identified those car features that might purposefully improve car efficiency and the technical efficiency trend from the 1970s to the 1990s.

\section{References}

[1] J.A. Czepiel, Competitive Marketing Strategy, Simon\&Shuster Custom Publishing, Upple Saddle River, NJ (1992).

[2] T. Levitt, Marketing Intangible Products and Product Intangibles, Harvard Business Review 59 (May-June), 94 (1981).

[3] S.J. Levy, Symbols for Sale, Harvard Business Review 37 (July-August), 117 (1959).

[4] G.L. Urban, and J.R. Hauser, Design and Marketing of New Products, Prentice-Hall, Englewood Cliffs, NJ (1980).
[5] M.B. Holbrook, and E.C. Hirshman, The Experiential Aspects of Consumption: Consumer Fantasies, Feelings, and Fun, Journal of Consumer Research 9, 132 (1982).

[6] T. Levitt, Marketing Success Through Differentiation of Anything, Harvard Business Review 58, 83 (1980).

[7] K. Lancaster, Consumer Demand: A New Approach, Columbia University Press, New York (1971).

[8] N. Capon, and R. Glazer, Marketing and Technology: A Strategic Coalignment, Journal of Marketing 51, 1 (1987).

[9] D. Sahal, The Generalized Distance Measure of Technology, Technological Forecasting and Social Change 9, 289 (1976).

[10] P.P. Saviotti, et al., An Approach to the Construction of Indexes of Technological Change and of Technological Sophistication-The Case of Agricoltural Tractors, Technological Change and Social Change 21, 133 (1982).

[11] P.P. Saviotti, and J.S. Metcalfe, A Theoretical Approach to the Construction of Technological Output Indicators, Research Policy 13, 141 (1984).

[12] B. Zaidman, and G. Cevidalli, The Technology Efficiency Index: A Method for Measuring Process Technologies, Technological Forecasting and Social Change 35, 51 (1989).

[13] E. Esposito, Technology Measurement: A Composite Approach, Technological Forecasting and Social Change 43, 1 (1993).

[14] K.L. Edwards, and J.T. Gordon, Further Research into a Convention for Measuring the State of the Art of Products or Processes, Technological Forecasting and Social Change 24, 153 (1983).

[15] J.P. Martino, Measurement of Technology Using Trade-Off Surfaces, Technological Forecasting and Social Change 27, 147 (1985).

[16] R.U. Ayres, Empirical Measures of Technological Change at the Sectoral Level, Technological Forecasting and Social Change 27, 229 (1985).

[17] K.E. Knight, A Functional and Structural Measurement of Technology, Technological Forecasting and Social Change 27, 107 (1985).

[18] H. Majer, Technology Measurement: The Functional Approach, Technological Forecasting and Social Change 27, 335 (1985).

[19] W.W. Cooper, L.M. Seiford, and K. Tore, Introduction to Data Envelopment Analysis and its Uses, Springer (2006).

[20] R.D. Banker, A. Charnes, and W.W. Cooper, Some models for estimating technical and scale inefficiencies in data envelopment analysis, Management Science 30, 1078 (1984).

[21] A. Charnes, W. Cooper, and E. Rhodes, Measuring the efficiency of decision-making units, European Journal Operations Research 3, 429 (1978).

[22] P. Andersen, and N.C. Petersen, A Procedure for Ranking Efficient Units in Data Envelopment Analysis, Management Science 39, 1261 (1993).

[23] K. Lovell, and P. Rouse, Equivalent standard DEA models to provide super-efficiency scores, Journal of the Operational Research Society 54, 101 (2003).

[24] J. Zhu, Robustness of the efficient DMUs in data envelopment analysis, European Journal of Operational Research 90, 451 (1996).

[25] GenteMotori, All issues of years: 1980, 1981, 1982,1991, 1992, 1993, Rusconi Editore, Milano.

[26] Quattroruote, All issues of years: 1970, 1971, 1972, 1980,1981, 1982,1991, 1992, 1993, Editoriale Domus, Milano. 
$E N G I N E^{i}=\left(\frac{P O W_{E N G}^{i}}{C A P_{E N G}^{i}} \cdot \frac{T_{E N G}^{i}}{M A S S^{i}}\right)^{\frac{1}{2}}$

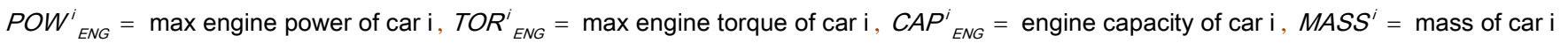

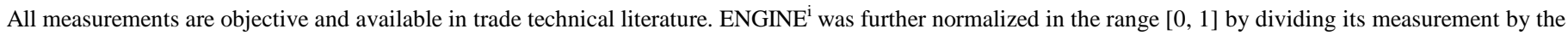
maximum ENGINE value in sample.

MOBILITY $Y^{i}=\left[\left(A C_{1}^{i} \cdot A C_{2}^{i} \cdot A C_{3}^{i} \cdot A C_{4}^{i} \cdot A C_{5}^{i} \cdot A C_{6}^{i}\right)^{\frac{1}{6}} \cdot\left(U_{1}^{i} \cdot U_{2}^{i} \cdot U_{3}^{i} \cdot U_{4}^{i}\right)^{\frac{1}{4}} \cdot V_{M A X}^{i}\right]^{\frac{1}{3}}$

$A C_{1}^{i}=$ acceleration of car $\mathrm{i}$ in the space $[0-1 \mathrm{~km}], A C_{2}^{i}=$ acceleration of car $\mathrm{i}$ after $400 \mathrm{~m}$

$A C_{3}^{i}=$ acceleration of car i to increase speed from 0 to $60 \mathrm{kmh}, A C_{4}^{i}=$ acceleration of car i to increase speed from 0 to $80 \mathrm{kmh}$,

$A C_{5}^{i}=$ acceleration of car $\mathrm{i}$ to increase speed from 0 to $100 \mathrm{kmh}, A C_{6}^{i}=$ acceleration of car i to increase speed from 0 to $120 \mathrm{kmh}$,

$U_{1}^{i}=$ pick up of car i to increase speed from $40 \mathrm{kmh}, U_{2}^{i}=$ pick up of car i to increase speed from 70 to $80 \mathrm{kmh}$,

$U_{3}^{i}=$ pick up of car $\mathrm{i}$ to increase speed from 70 to $100 \mathrm{kmh}, U_{4}^{i}=$ pick up of car $\mathrm{i}$ to increase speed from 70 to $120 \mathrm{kmh}$,

$U_{4}^{i}=$ pick up of car i to increase speed from 70 to $120 \mathrm{kmh}, V_{\text {MAX }}=$ max speed of car $\mathrm{i}$

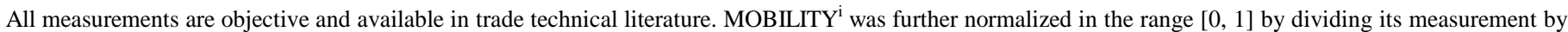
the maximum MOBILITY value in sample.

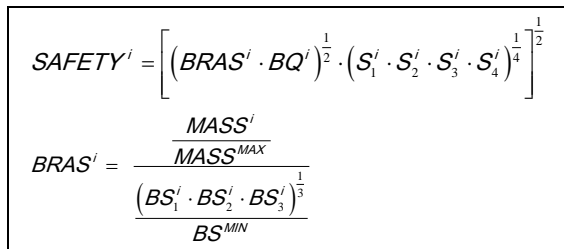

$B Q^{i}=$ subjective measure of the braking quality of car i , $B R A S^{i}=$ braking space of car i, $M A S S^{i}=$ mass of car i ,

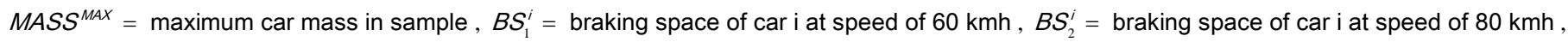

$B S_{3}^{i}=$ braking space of car i at speed of $100 \mathrm{kmh}, B S_{3}^{i}=$ braking space of car i at speed of $100 \mathrm{kmh}$,

$B S^{M I N}=\operatorname{minimum}\left(B S_{1}^{i} \cdot B S_{2}^{i} \cdot B S_{3}^{i}\right)^{\frac{1}{3}}$ in sample, $S_{1}^{i}=$ subjective measure of the steering quality of car $\mathrm{i}$,

$S_{2}^{i}=$ subjective measure of the visibility quality of car i , $S_{3}^{i}=$ subjective measure of the road holding quality of car i

$S_{4}^{i}=$ subjective measure of the safety equipment quality of car $\mathrm{i}$

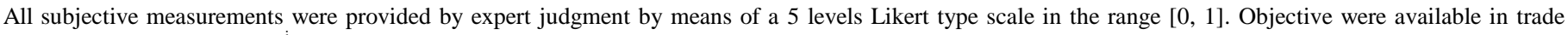
technical literature. SAFETY ${ }^{i}$ was further normalized in the range $[0,1]$ by dividing its measurement by the maximum SAFETY value in sample.

QUALITY $Y^{i}=\left[\left(N O_{1}^{i} \cdot N O_{2}^{i} \cdot N O_{3}^{i} \cdot N O_{4}^{i}\right)^{\frac{1}{4}} \cdot\left(I Q_{1}^{i} \cdot I Q_{2}^{i} \cdot I Q_{3}^{i} \cdot I Q_{4}^{i} \cdot I Q_{5}^{i}\right)^{\frac{1}{5}} \cdot C O^{i}\right]^{\frac{1}{3}}$

$N O_{1}^{i}=$ internal noise level of car i at speed of $60 \mathrm{kmh}, N O_{2}^{i}=$ internal noise level of car i at speed of $80 \mathrm{kmh}$,

$N \mathrm{O}_{3}^{i}=$ internal noise level of car i at speed of $100 \mathrm{kmh}, N O_{4}^{i}=$ internal noise level of car $\mathrm{i}$ at speed of $120 \mathrm{kmh}$,

$I Q_{1}^{i}=$ subjective measure of the car i internal fittings quality, $I Q_{2}^{i}=$ subjective measure of the car i internal ventilation and climate quality,

$I Q_{3}^{i}=$ subjective measure of the car i internal equipment quality , $I Q_{4}^{i}=$ subjective measure of the car $\mathrm{i}$ internal space quality

$I Q_{5}^{i}=$ subjective measure of the car i driving seat quality , $C O^{i}=$ subjective measure of the car i travel comfort quality

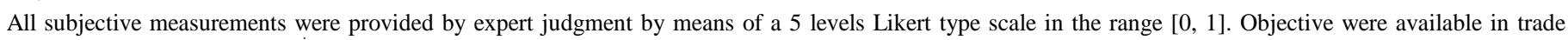
technical literature. QUALITY ${ }^{\mathrm{i}}$ was further normalized in the range $[0,1]$ by dividing its measurement by the maximum QUALITY value in sample.

$P U C^{i}=\left(F U_{1}^{i} \cdot F U_{2}^{i} \cdot F U_{3}^{i}\right)^{\frac{1}{3}}$

$F U_{1}^{i}=$ fuel consumption of car i in city driving, $F U_{2}^{i}=$ fuel consumption of car i at speed of $90 \mathrm{kmh}$,

$F U_{3}^{i}=$ fuel consumption of car i at speed of $120 \mathrm{kmh}$

$P P C_{1993}^{i}=\frac{\mathrm{CP}(1993)}{100} \cdot P P C_{t}^{i}$

,$P P C_{1993}^{i}=$ purchasing price of car i at year 1993, $P P C_{t}^{i}=$ purchasing price of car $\mathrm{i}$ sold at year $\mathrm{t}$ 